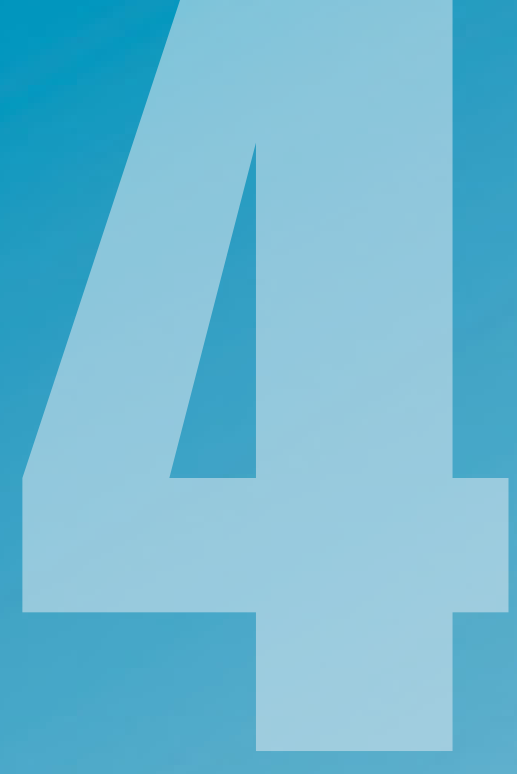

ÁMBITOS

REVISTA

INTERNACIONAL

DE COMUNICACIÓN

$N^{\circ} 46$

EDICIÓN OTOÑO

2019

ISSN: 1139-1979

E-ISSN: 1988-5733

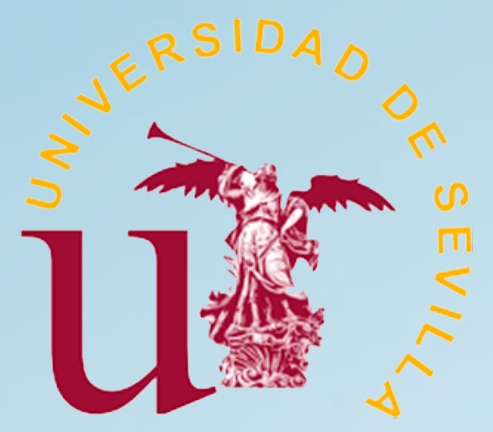




\section{ÍNDICE}

MONOGRAFICOS MONOGRAPHS

Presentación Monográfico. Comunicación emergente. Experiencias para el cambio social

Dra. Nereida López Vidales

Los formatos de televisión más consumidos por los jóvenes: telerrealidad y empoderamiento de la audiencia

Most consumed televisión formats by young people: real TV and the empowerment of the audience Nereida López Vidales, Leire Gómez Rubio, Elena Medina de la Viña

Nuevas herramientas, viejas costumbres El Contenido Generado por los Usuarios sobre el cambio climático en YouTube

New tools, old habits User Generated Content about climate change on YouTube

David Vicente Torrico

Tratamiento periodístico de personas LGTBIQ+ refugiadas: estudio de caso sobre Pride Barcelona 2018

Journalistic treatment of LGTBIQ+ refugees: case study on Pride Barcelona 2018

Hadriel Theodoro, Amparo Huertas Bailén

Tiempo Muerto, estudio de caso de un proyecto transmediático para la consecución de competencias universitarias

Tiempo Muerto, case study of a transmediatic project for the achievement of university competences Jose L. Carreño Villada, Miguel Ángel Díaz Monsalvo

Los universitarios millennials: uso de redes sociales y relación con las marcas

University Millennials: use of social media and engage with brands

Pedro Pablo Marín Dueñas, Esther Simancas González

Ali Ferzat: De la caricatura comunicativa en papel a la caricatura activista en los medios digitales

Ali Ferzat: From political cartoons in papers to political cartoons in digital media

Salud Adelaida Flores Borjabad

Direito à informação e literacia midiática: Reflexões sobre a questão do acesso

Right to information and media literacy: Reflections on the question of acce

Christiane Delmondes Versuti 
Eficacia de los influencers como recurso publicitario en la estrategia de los anunciantes locales Efficacy of influencers as an advertising resource in the strategy of local advertisers

Isabel Iniesta-Alemán

As redes sociais como ferramenta de marketing em instituições de ensino superior no Brasil Social networks as a marketing tool in higher education institutions in Brazil

Alcino Ricoy JR, Rogério Eduardo Rodrigues Bazi

Estudio sobre la conceptualización y el tratamiento informativo de la violencia de género en la prensa digital cubana

Study about the conceptualization and information treatment of gender violence in the Cuban digital press

Regla Ismaray Cabreja Piedra, Karina Escalona Peña

\section{ARTÍCULOS ARTICLES}

Uso de Twitter durante los debates electorales televisados en los comicios andaluces de 2018 The use of Twitter during the televised electoral debates in the 2018 Andalusian elections Julia Fontenla Pedreira, Erika Conde Vázquez, Carmen Máiz Bar

Quem averigua as notícias, os algoritmos ou jornalistas? A lógica crítica de C. S.

Peirce como processo de identificação de uma Fake News

Who checks the news, algorithms or journalists? The critical logic of C. S. Peirce as a

process for identifying a Fake News

Adelino de Castro Oliveira Simões Gala, Vania Baldi, Universidad de Aveiro

\section{RESEÑAS REVIEWS}

Nuevo ecosistema comunicativo digital: El consumidor

Juan Carlos Figuereo Benítez

Corpus toponímic de Beniarrés

Bianca Sánchez-Gutiérrez

The Future Computed. La inteligencia artificial y su papel en la sociedad y Pulsa actualizar. La aventura de redescubrir el alma de Microsoft y concebir un futuro mejor para todos 


\title{
As redes sociais como ferramenta de marketing em instituições de ensino superior no Brasil
}

\author{
Social networks as a marketing tool in higher \\ education institutions in Brazil
}

\author{
Alcino Ricoy JR, Pontifícia Universidade Católica de Campinas \\ Rua Professor Dr. Euryclides de Jesus Zerbini, n 1.516 \\ Parque Rural Fazenda Santa Cândida - 13087-571 - Campinas, SP, (Brasil) \\ alcinoricoy@gmail.com | Orcid: https://orcid.org/0000-0001-9130-9473 \\ Rogério Eduardo Rodrigues Bazi, Pontifícia Universidade Católica de Campinas \\ Rua Professor Dr. Euryclides de Jesus Zerbini, n 1.516 \\ Parque Rural Fazenda Santa Cândida - 13087-571 - Campinas, SP, (Brasil) \\ bazi@puc-campinas.edu.br | Orcid: https://orcid.org/0000-0001-8319-4522
}

DOI: http://dx.doi.org/10.12795/Ambitos.2019.i46.10

\begin{abstract}
Resumo
O propósito do artigo possui como panorama a questão da utilização das redes sociais e sua inserção no processo de marketing e comunicação de Instituições de Ensino Superior Católicas no Brasil. Vivencia-se uma realidade na qual atores sociais individuais e coletivos agem por meio de discursos, relacionando-se de forma mediada e midiatizada. $\mathrm{E}$ as redes sociais digitais se constituem como espaços de disputa de sentidos, em que as organizações atuam na busca de legitimação perante seus públicos e a sociedade. O estudo revela se as postagens das IES, Universidade Católica Dom Bosco e a Pontifícia Universidade Católica de Goiás, ambas brasileiras, na rede social Facebook demonstram ações de marketing educacional. Utilizou-se da pesquisa quali-
\end{abstract}


quantitativa de caso, com a utilização da ferramenta de mensuração Scup. O estudo desperta o interesse para os estudos do marketing educacional, mas especificamente em instituições católicas e insere a midiatização no processo de divulgação das ações de marketing. Os resultados da pesquisa mostraram que as duas Universidades analisadas se valem do uso das redes sociais como ferramentas de marketing, confirmados pelo alto engajamento das suas publicações. Com o estudo foi possível estabelecer relações entre a midiatização, os estudos do marketing e a questão dos conceitos das redes sociais digitais. A partir da reflexão e dos dados coletados, a perspectiva é de que a visibilidade midiática organizacional, no contexto de midiatização e mídias sociais digitais, constrói-se na articulação com o engajamento, gerado pela ativação de público-alvo e pela qualidade dos conteúdos escolhidos, disseminados via as redes sociais.

\section{Abstract}

The purpose of this article is to analyze the use of social networks and their insertion in the marketing and communication process of Catholic Higher Education Institutions in Brazil. A reality is experienced in which individual and collective social actors act through discourses, interacting in a mediated and mediatized way. And the digital social networks constitute as spaces of the dispute of meanings, in which the organizations search for the legitimacy for its public and society. The study reveals whether the posts of the HEls, Catholic University Don Bosco and the Pontifical Catholic University of Goias, both Brazilian, in the social network Facebook demonstrate educational marketing actions. The qualitative-quantitative research studied was used with the Scup measurement tool. The study awakens the interest for studies of educational marketing, but specifically in Catholic institutions and inserts mediatization in the process of dissemination of marketing actions. The results of the research showed that the two Universities analyzed use social networks as marketing tools, confirmed by the high engagement of their publications. With the study, it was possible to establish relations between mediatization, marketing studies and the question of the concepts of digital social networks. From the reflection and collected data, the perspective is that the organizational media visibility, in the context of mediatization and digital social media, is built in the articulation with the engagement, generated by the activation of the target audience and the quality of the chosen content, disseminated via social networks.

Palavras-chave: Comunicação, Universidade Católica, Midiatização, Tecnologia e Redes Sociais.

Keywords: Communication, Catholic University, Mediatization, Technology and Social Networks. 


\section{INTRODUÇÃO}

O propósito do presente artigo possui como panorama a questão da utilização das redes sociais e sua inserção no processo de marketing e comunicação de Instituições de Ensino Superior (IES) Católicas, localizadas no Brasil. Deseja-se compreender se as postagens das IES na rede social Facebook demonstram ações de marketing educacional.

Para tanto, o artigo debruça-se nas estratégias de marketing aplicadas em duas IES Católicas: a Universidade Católica Dom Bosco (UCDB), na cidade de Campo Grande, Estado de Mato Grosso, e a Pontifícia Universidade Católica de Goiás (PUC Goiás), na cidade de Goiânia, Estado de Goiás. Justifica-se a escolha pelo fato de serem duas Universidades circunscritas numa mesma região geográfica brasileira, o que sugere uma identidade cultural regionalizada. Também, ao fato de as duas IES apresentarem um grande número de alunos matriculados - a Universidade Católica Dom Bosco, atualmente, conta com 9 mil alunos de graduação e a Pontifícia Universidade de Goiás com cerca de 19 mil alunos, segundo portal do Ministério da Educação (MEC) ${ }^{1}$ brasileiro. As duas instituições mantêm forte aderência em ativações, postagens e seguidores nas redes sociais. A PUC Goiás contabiliza mais de 72 mil seguidores no Facebook e, a UCBD, 96 mil seguidores, de acordo com os dados colhidos nas páginas oficiais das duas IES em outubro de 2018.

Para a coleta e posterior análise dos dados, mensuramos o engajamento gerado com as postagens, por meio dos compartilhamentos de publicações no período analisado, de $1^{\circ}$ de julho a 30 de setembro de 2018, nas páginas oficiais do Facebook das duas IES.

Isto posto, entendemos que analisar as práticas relacionadas à visibilidade organizacional nas redes sociais constitui aspecto essencial para pensar a comunicação de forma estratégica e, portanto, estudos que revelam as dinâmicas das ações de marketing nas redes sociais, particularmente em instituições de ensino, constituem importante instrumento de gestão interna.

\section{A MIDIATIZAÇÃO E AS REDES SOCIAIS}

Com os avanços das tecnologias digitais de comunicação e informação, experimentamos uma profunda reestruturação da sociedade, caracterizada por mais flexibilidade e descentralização do gerenciamento das empresas, além de formação de redes internas e relações de mercado das organizações.

Fausto Neto (2008, p. 93) observa que, em um período que se pode denominar "sociedade dos meios", as mídias "(...) teriam uma autonomia relativa, face à existência dos demais campos". Com isso, na sociedade midiatizada, "a cultura midiática se 
converte na referência sobre a qual a estrutura sócio-técnica-discursiva se estabelece, produzindo zonas de afetação em vários níveis da organização e da dinâmica da própria sociedade".

A atual configuração social, baseada em uma sociedade globalizada, conectada, em que as distâncias se apresentam com pouca extensão, sugere que não observemos a mídia de forma isolada, mas em sua relação com as instituições culturais e sociais. A justificativa para tal afirmação está no fenômeno da midiatização, que destaca a mídia como parte do funcionamento de outras instituições que, em maior ou menor grau, submetem-se à sua lógica (Hjarvard, 2015).

Como consequência desse fenômeno, o autor detalha que "a interação social dentro das respectivas instituições, entre instituições e na sociedade em geral acontece através dos meios de comunicação" (Hjarvard, 2015, p. 64). Alinhado a isso, entender esse fenômeno é fundamental para observar as relações entre mídia e sociedade, no momento em que a lógica da mídia é base de relações sociais (Barichello, 2014).

Para Ferreira (2007), a midiatização pode ser compreendida como a articulação entre dispositivos midiáticos, processos de comunicação e processos sociais. Essa triade se intercede e os elementos influenciam um ao outro, criando relações possíveis para interpretar a midiatização. Para o autor, a comunicação é um meio pelo qual os processos fluem, de maneira contínua e concreta.

Contribuindo com a exposição, na perspectiva de Martín-Barbero (2009) o receptor não está inerte no discurso produzido pela mídia de massa, mas é participante de uma mediação através da sua inserção cultural. Não existe mais uma rua de mão única, em que a mensagem mediada não tem impacto sobre quem a recebe. Com isso, o receptor faz parte do processo da comunicação com suas atividades e interações.

Essa perspectiva diferencia ligeiramente do pensamento comum sobre a midiatização que a relaciona facilmente com as tecnologias digitais. Para Braga (2012), a midiatização não se configura somente pela ampliação da indústria cultural na sociedade, ou pelas inovações tecnológicas disponibilizadas- embora não possam ter sua visibilidade negada- mas, pelas ações intrínsecas da mídia, de vários setores da sociedade ganhando um caráter, também, de regulamentação político-social, o que de certa forma se aproxima da perspectiva institucionalista de Hjarvard (2015).

A visão institucionalista de Hjarvard (2015, p. 21) sugere que a "midiatização é caracterizada por um desenvolvimento bilateral, no qual a mídia se tornou institucionalizada dentro de outros domínios sociais, ao mesmo tempo que adquiriu o status de instituição social em si mesma". 
Face a este pressuposto, Hjarvard (2012) também aponta que os contextos institucionais não são mais definidos pelo seu locus e estão atrelados à virtualização. Para o autor, a maioria das instituições ainda mantém bases físico-geográficas como estruturas importantes para a práxis social. "A novidade é que esses lugares e edifícios agora interagem com lugares e espaços virtuais, e a realidade e as formas de interação que ocorrem no mundo virtual também têm consequências para a práxis social na localidade física" (Hjarvard, 2012, p. 83). Ou seja, a atuação das organizações nos espaços virtuais constitui um novo espaço de práticas, mas também interfere na atuação das organizações fora do ambiente digital. Os espaços sociais, de maneira especial, os espaços sociais digitais se sobrepõem aos geográficos, dando um novo sentido para as localizações que se configuram.

Ainda de acordo com Hjarvard (2015, p. 218), a sociedade midiatizada é marcada pela constituição de um "individualismo brando dependente de laços sociais fracos". E, ainda, além de possibilitar novas formas de socialização, os meios de comunicação configuram uma socialização dos gostos e uma padronização dos estilos de vida, bem como constituem novos espaços para a obtenção de reconhecimento dos indivíduos diante da sociedade. Com isso, redes sociais como Facebook e Linkedln, mais que canais de comunicação entre os usuários, tornam-se lugares para o reconhecimento das realizações dos indivíduos diante da sua rede de amigos ou contatos.

Durante o processo de midiatização, "a mídia institucionalizada passa a desempenhar funções específicas na sociedade, com implicações específicas diante das instituições sociais com as quais se relaciona, ao mesmo tempo que, reciprocamente, sofre influências das mesmas". (Hjarvard, 2015, p. 214).

Entretanto, instituições não podem ser confundidas com organizações, que são entidades específicas e empíricas que podem ser parte de uma instituição e que também interagem com a sociedade. De um ponto de vista sociológico, uma instituição é um domínio ou campo da vida social identificável que é governado por um determinado conjunto de regras formais e informais, apresenta uma estrutura particular, desempenha determinadas funções sociais, e aloca recursos para a ação social de maneiras variadas. Família, política e religião, por exemplo, podem ser consideradas instituições, a partir dessa perspectiva.

Portanto, a mídia constitui um espaço central de visibilidade, seja no fortalecimento da marca institucional, nas ações de marketing ou na divulgação de informações. Ter visibilidade é vital para esse relacionamento, permeado pelas redes sócias digitais. Compreende uma produção diversificada e descentralizada, com a produção de conteúdo em diferentes tipos de mídia, plataformas e com formatos distintos de organização, funcionamento e regulamentação. 
Diante deste contexto, nota-se que as instituições superiores de educação necessitam atuar mais fortemente com o marketing nas mídias sociais digitais, uma vez que no processo de midiatização a atuação de todos os atores envolvidos, instituição e público, principalmente, estão inseridos em um processo comunicativo de deslocamento do poder, visto que ambos podem são visíveis com as questões de seu interesse. Há, sempre, nas mídias sociais digitais, um equilíbrio entre os atores envolvidos.

As redes sociais na internet são constituídas de representações dos atores sociais e de suas conexões, como citado por Recuero (2012). Essas representações, por um lado, são, geralmente, individualizadas e personalizadas e podem ser constituídas, por exemplo, de um perfil no Facebook, um weblog ou mesmo um fotolog, ou em outra rede social.

As conexões são os elementos que vão criar a estrutura na qual as representações formam as redes sociais. Essas conexões, na mediação da internet, podem ser de tipos variados, construídas pelos atores através da interação, mas mantidas pelos sistemas on-line.

Recuero (2012, p. 12) aponta as redes sociais na internet como ferramentas populares e emergentes nessas novas mediações, capazes de difundir informações globalmente. Assim, por exemplo, o Facebook pode representar diversas redes sociais que são constituídas pelos atores que ali se cadastram e interagem.

Por sua vez, Castro (2017) considera que com o surgimento das redes sociais, em especial do Facebook, ninguém pode pensar a sua vida e os processos de sua formação à margem das tecnologias que o rodeiam. Para o autor, essa é a prova de que cada geração desenvolve destrezas particulares no contato com um ecossistema de dispositivos tecnológicos que, por sua vez, incorporam valores, uma estética específica, novas formas de ver e experimentar o mundo.

Massimo Di Felice (Di Felice, 2011-2012) disserta sobre o processo em que a comunicação se insere. O autor diz que, com as redes digitais, a comunicação se arquiteta em um processo interativo, com a "ausência de centro e da superação da estrutura frontal (emissor-receptor), que marcou a história das interações comunicativas desde o teatro até a TV", dando "a possibilidade para todos os membros de ter acesso a todas as informações, independentemente de suas localidades e posições". (Di Felice, 2011-2012, p. 13). O autor afirma que:

A passagem de um modelo comunicativo baseado na separação identitária entre emissor e receptor e num fluxo comunicativo bidirecional para um modelo de circulação das informações em rede, no qual todos os atores desenvolvem simultaneamente a atividade midiática de emissão e recepção, altera a prática e o significado do ato de comunicar. A partir dessa transformação, tal ato torna-se o 
resultado da interação com os círculos informativos e a consequência dos estímulos contínuos das interfaces e das distintas extensões comunicativas, evidenciando como o horizonte das tecnologias da comunicação. (Di Felice, 20112012, p. 13).

A mediação da internet proporcionou outro fator importante: a complexidade da interconexão dos indivíduos. A internet proporciona, assim, que as conexões das redes sociais sejam ampliadas no espaço on-line. Assim, elas podem ser de dois tipos, segundo Recuero (2012): aquelas emergentes, que caracterizam laços construídos através da conversação entre os atores (que vão gerar as redes emergentes), e aquelas de filiação ou associação, caracterizadas pela manutenção da conexão realizada pelo software ou site utilizados (que vão gerar as redes de filiação). Enquanto as primeiras passam pelo processo de aprofundamento do laço social, as segundas podem jamais ter qualquer interação, exceto no momento de estabelecimento da conexão.

Ainda que milhares de mensagens, posts no Facebook, fotos e imagens sejam publicados todos os dias e circulem pelas mais variadas esferas sociais, pouco se faz no sentido de compreender seus efeitos e impactos, suas condições de produção e, mesmo, as formações discursivas a que se filiam.

Isso se deve à complexidade dos designs metodológicos necessários para tais estudos, especialmente no que diz respeito à coleta e análise dos dados em larga escala. São os atores sociais ou as comunidades virtuais os responsáveis por criar e reorganizar os espaços dentro dos meios digitais.

Dessa maneira, segundo Lemos (2002, p. 24) apud Recuero (2008, p. 138), "as comunidades virtuais eletrônicas são agregações em torno de interesses comuns, independentes de fronteiras ou demarcações territoriais fixas". Dessa forma, intuímos que as mídias sociais vêm ao encontro de uma característica presente na pósmodernidade. Com a ausência de fronteiras fixas e até de identidades bem definidas, as mídias sociais servem como uma forma de os usuários poderem interagir de acordo com interesses em comum, sem precisar encontrar-se ou estar dentro da mesma cidade, por exemplo, para interagir.

\section{A MIDIATIZAÇÃO NO CONTEXTO DO MARKETING EDUCACIONAL}

Notadamente, o efeito 'rede' da sociedade midiatizada interfere nas decisões e condiciona uma estrutura de comunicação mais ágil e ativa por parte das instituições de ensino.

A convergência tecnológica levou a integração rápida com marketing digital. Em um mundo altamente tecnológico, as pessoas anseiam por um envolvimento profundo. A intensificação da tecnologia e conectividade motiva uma convergência do 
comportamento humano que já vem sendo percebida nos últimos anos e motivam mudanças nas práticas de marketing, em que novas tendências surgem, tais como a economia "compartilhada", a economia do "agora", marketing de conteúdo, a estratégia de gestão de relacionamento com os clientes através das redes sociais, intensificação do uso de Big Data, entre outras.

Neste momento de transição, o marketing 4.0 ocupa um local de destaque no ambiente comunicativo:

(...) os profissionais de marketing precisam embarcar na mudança para um cenário de negócios mais horizontal, inclusivo e social. O mercado está se tornando mais inclusivo. A mídia social elimina barreiras geográficas e demográficas, permitindo as pessoas se conectarem e se comunicarem, e, às empresas, inovar por meio da colaboração. (Kotler, 2017, p. 29).

Para Kotler (2017), os consumidores estão adotando uma orientação mais horizontal. Desconfiam cada vez mais da comunicação de marketing das marcas e preferem confiar no círculo social (amigos, família, fãs e seguidores).

Com isso, o processo de compra dos consumidores está se tornando mais exponencial social do que nunca. Essa nova geração de consumidores está emergindo globalmente, e são jovens, urbanos, de classe média, com mobilidade e conectividade atuante.

O marketing educacional, que é uma ferramenta do marketing, aproveita todas suas estratégias para empregar nos processos de comunicação das instituições de ensino. Há pelo menos uma década, grande parte das instituições não encaravam ações de marketing como parte fundamental do processo de captação e retenção de alunos.

O público interessado em ensino superior busca informações que o ajude a refletir sobre o tipo de curso que deseja fazer, sobre a área de ensino que lhe interessará mais e, claro, qual instituição escolheria. Tudo isso demanda muita pesquisa e torna-se possível pelos aparatos tecnológicos que estão disponíveis aos jovens e seus pais. São milhares de vídeos, conteúdos dos mais variados, campanhas publicitárias e ações de relacionamento na busca de satisfazer a fome de informação dos clientes de uma geração conectada.

Mergulhado nesse cenário, o marketing das instituições de ensino precisa estar on-line e conectado, pois é no digital que os potenciais alunos estão buscando reconhecer suas principais características antes da escolha. É o momento de testar o produto ou serviço, através das suas redes de relacionamento.

Como indicado no censo de 2016 do Instituto Nacional de Estudos e Pesquisas Educacionais Anísio Teixeira (INEP), órgão do Ministério da Educação no Brasil, são 
mais de 2 mil instituições de ensino superior no país. Com a horizontalização do conteúdo, via web, o cenário de investimentos em estratégias de marketing das IES, como apresenta a Pesquisa da Edu Trends ${ }^{2}$ 2016, tornou-se uma relevante característica de relacionamento com alunos, professores e instituições. A pesquisa reforça a importância da influência digital nos relacionamentos entre IES e seu público interno e externo.

Os dados apresentados pela pesquisa Edu Trends 2016 foram obtidos por meio de uma pesquisa online, respondida por 230 instituições de ensino de todo o Brasil, no período de 10 a 26 de agosto de 2016. Nota-se, a partir dos dados da pesquisa Edu Trends 2016, como as IES estão se posicionando com os investimentos em marketing, conforme Figura 1.

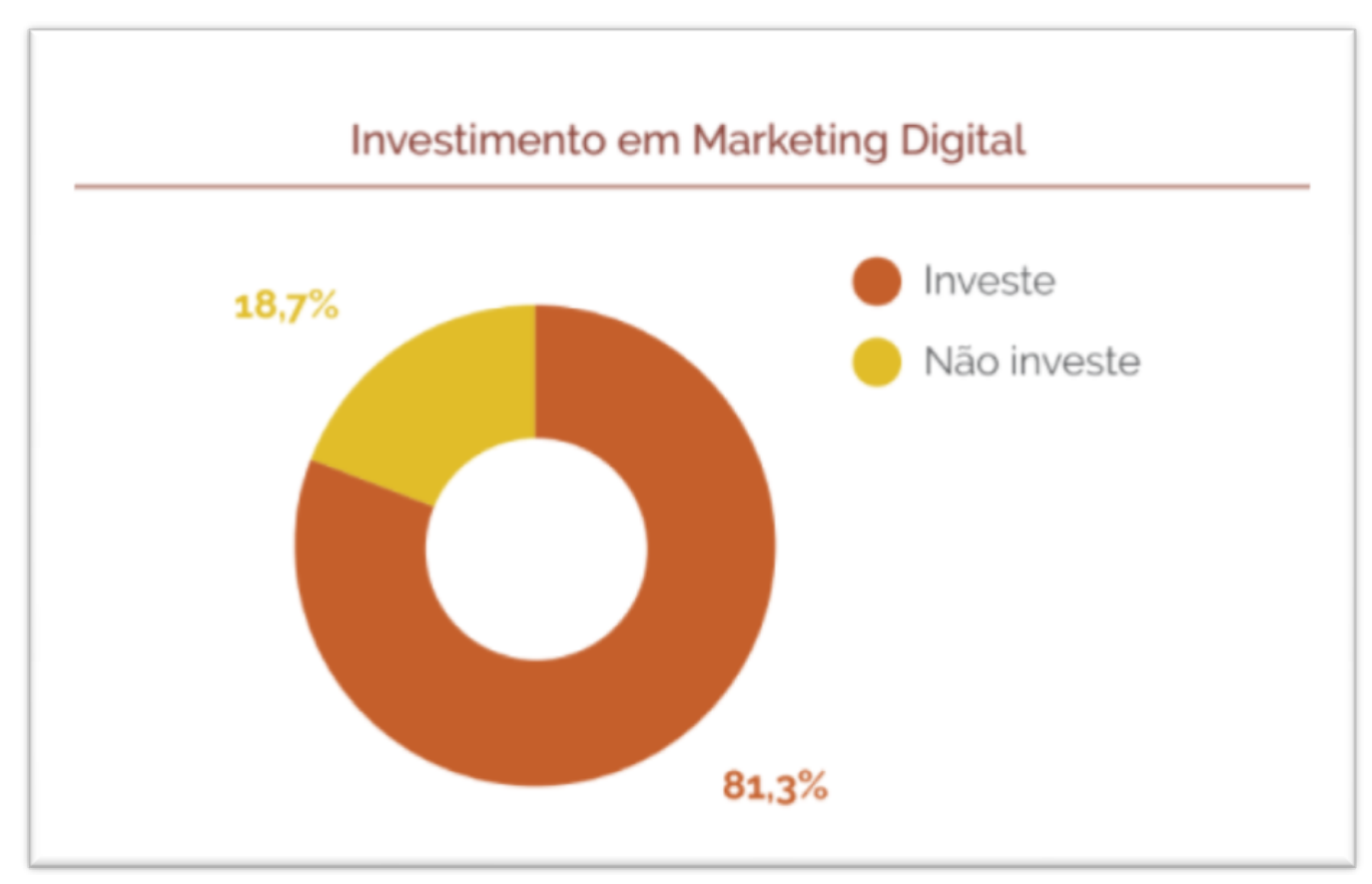

Figura 1 - Investimento em Marketing digital 2016

Fonte: Pesquisa Edu Trends

A pesquisa indicou que $81,3 \%$ das IES investem em Marketing Digital, ou seja, estão com presença na internet de alguma forma, muito embora ainda existam altos investimentos em marketing off-line.

Com os possíveis alunos cada vez mais imersos nesse meio, o digital se mostra como uma das possibilidades mais eficientes para a aproximação da instituição com seu público. Isso porque utilizar essa modalidade de marketing significa aproveitar os canais 
digitais de forma estratégica, ou seja, usar as redes sociais, o e-mail e os buscadores, como o Google, para expor a marca e atrair os alunos em potencial.

Entre as principais estratégias das IES na mídia digital estão as publicações em redes sociais, conforme sugere a Figura 2, que carregam conteúdos das instituições e buscam engajar seus públicos interno e externo. Quase a totalidade das IES que se apoderaram da mídia digital respondeu à pesquisa indicando que sua principal estratégia são postagens em redes.

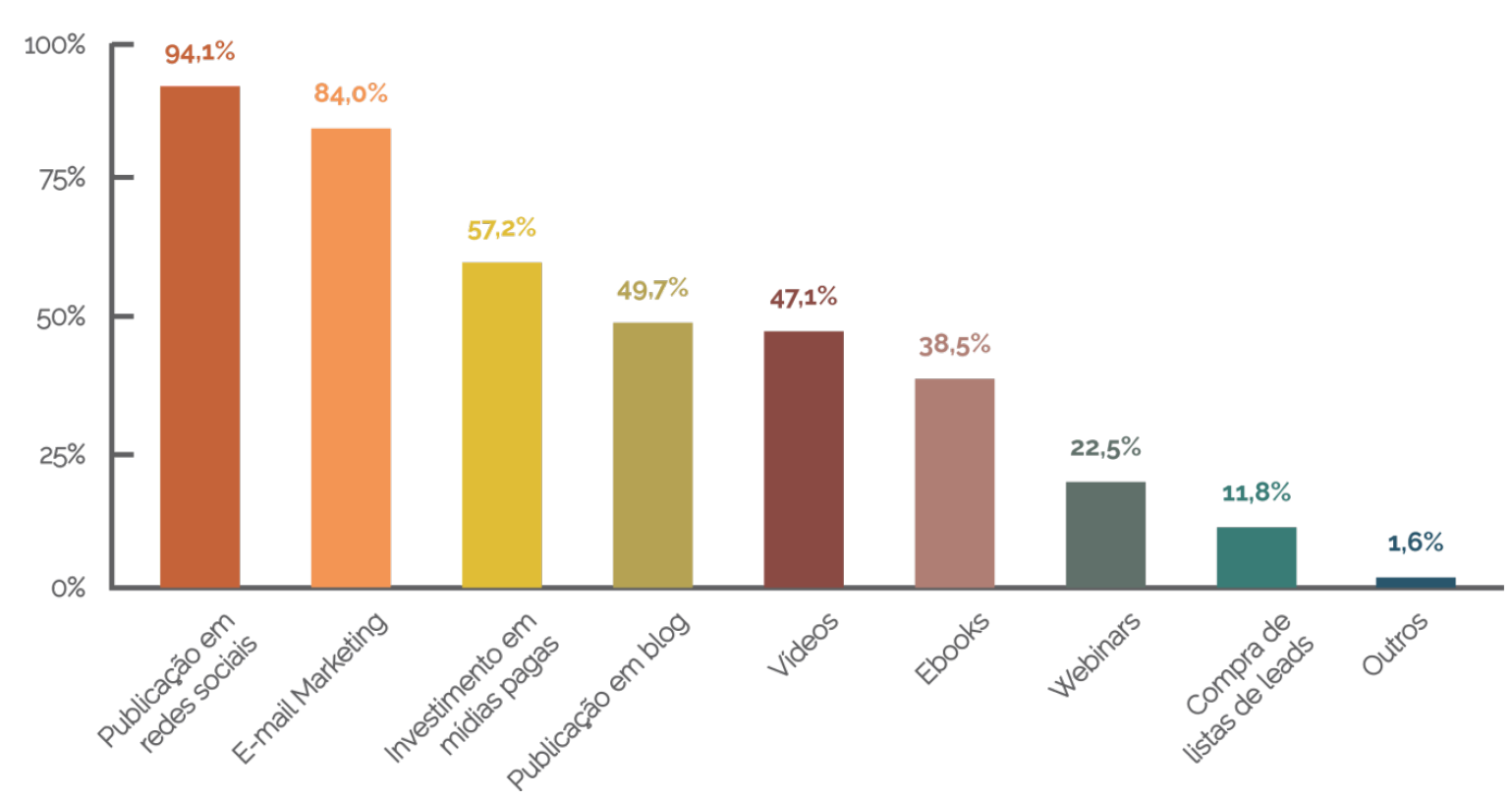

Figura 2 - Estratégias de marketing digital

Fonte: Pesquisa Edu trends 2016

Nota-se que o objetivo das IES, ao ingressar definitivamente no marketing digital, está focado na conversão de leads, ou seja, um cadastro de pessoas para a efetivação de matrículas para a universidade, demonstrado pela Figura 03, tornando-se o maior dos desafios do profissional de marketing que atua no segmento. Essas evidências deixam clara a importância das ações para a sustentabilidade das instituições, ou seja, as estratégias são vitais para a geração de novos alunos. 


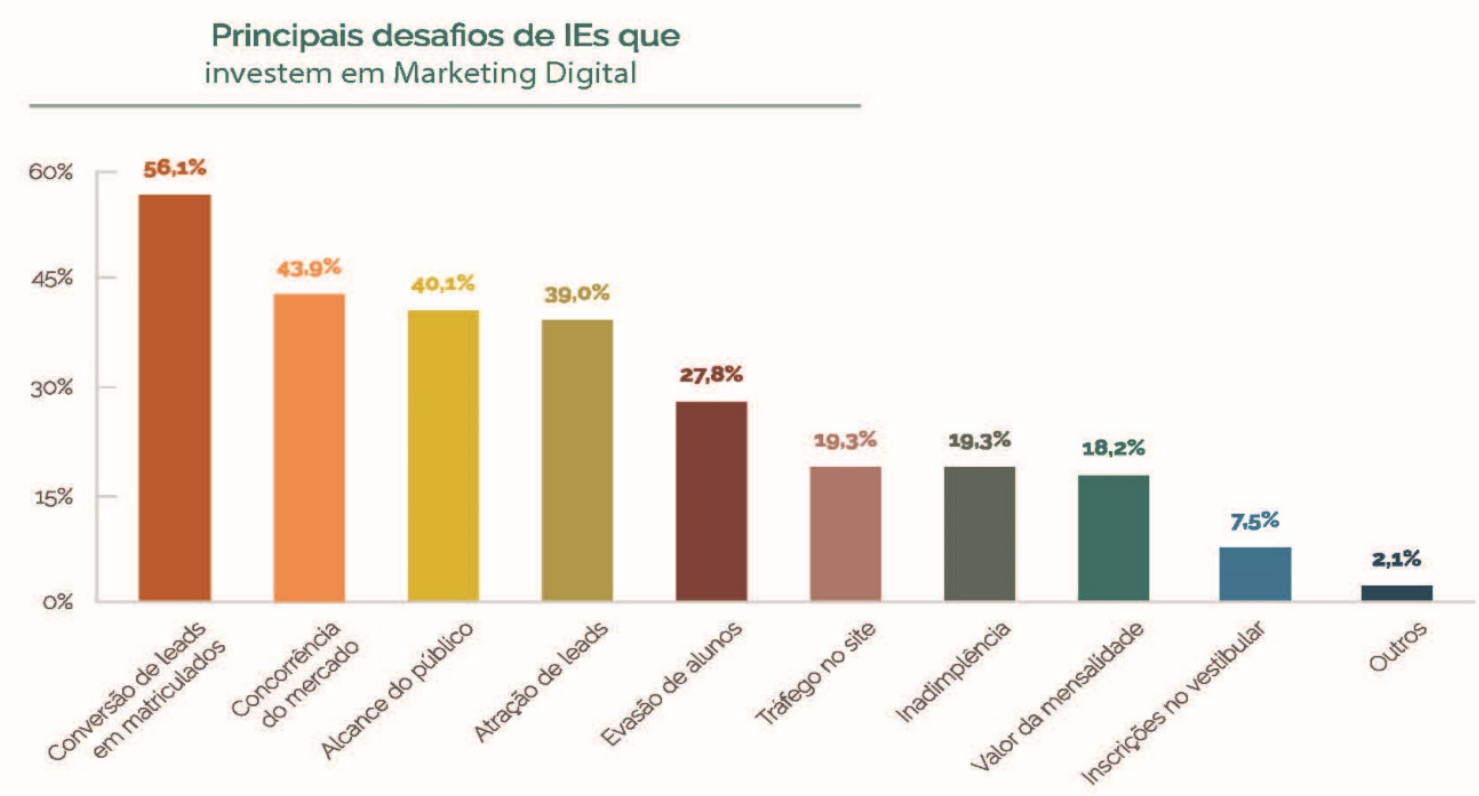

Figura 3 - Principais desafios de IES que investem em Marketing digital Fonte: Pesquisa Edu trends 2016.

As instituições que investem em comunicação e marketing já identificam que o engajamento digital é um objetivo - e um trunfo - a ser perseguido na atualidade. Porém, o real significado do termo ainda suscita diferentes interpretações, apesar de normalmente referir-se a algum tipo de participação da audiência.

Para Cerqueira e Silva (2011, p. 112), o significado de engajamento, se pensarmos em termos semânticos, nos transporta à filiação a uma linha ideológica, filosófica ou outra, e também pode ser definida como "pôr-se a serviço de uma ideia, de uma causa, de uma coisa ou empenhar-se em dada atividade ou empreendimento", afirmam os autores.

Cerqueira e Silva (2011, p.113) ainda argumentam que por meio das redes sociais também é possível promover o engajamento dos consumidores. Quando se refere a engajamento, os autores afirmam que - "é o nível de envolvimento, interação, intimidade e influência que um indivíduo tem com uma marca ao longo do tempo".

Esse conceito, ao substituir o termo mercadológico de "consumidor" por "indivíduo", alarga o entendimento sobre engajamento ao contemplar pessoas que ainda não tiveram a oportunidade de adquirir um produto ou serviço vinculado à marca, mas se esforçam para propagar suas características e valores com seus pares. Um elogio postado no Facebook por um potencial cliente, ou seja, por um simpatizante de 
determinada marca pode constituir um exemplo de engajamento digital. $\mathrm{O}$ fato de ainda não ser propriamente um consumidor do produto ou serviço não o desabilita a impactar positivamente familiares, amigos e conhecidos.

Devido a flexibilidade epistemológica do conceito de engajamento, citado anteriormente, o presente estudo serviu-se de quatro elementos, de acordo com Cerqueira e Silva (2011), para a identificação do nível de engajamento das IES analisadas, sendo, portanto:

1. Envolvimento: considerado o nível mais básico do engajamento. É marcado por contatos simples entre o indivíduo e a marca, tais como visita ao site da empresa, tempo gasto em um website e páginas visitadas. O entendimento desse nível é importante para o aprofundamento dos demais estágios e pode servir de baliza para um melhor gerenciamento de conteúdo institucional através das plataformas digitais que estão sendo acionadas para impactar a audiência;

2. Interação: esse elemento abrange itens que exigem mais ação por parte do indivíduo, tais como solicitação de informação adicional ou compra de produtos e serviços, comentários em blogs, conexões em redes sociais digitais e download de fotos e vídeos. O crescimento e a estruturação das comunidades virtuais no ciberespaço estão sendo decisivos para o entendimento desses comportamentos emergentes e desempenham um papel fundamental para o cálculo do valor do cliente. Ao cruzar informações sobre mídias sociais na internet e comércio eletrônico, através de ferramentas disponíveis no mercado, é possível verificar se os produtos mais populares, ou seja, mais procurados, estão sendo efetivamente adquiridos pelos internautas;

3. Intimidade: comporta os sentimentos e opiniões que os indivíduos cultivam ou tecem em relação a uma marca, e normalmente são representados pelas palavras utilizadas ao se referirem a ela e pela natureza dos conteúdos que são gerados. A percepção, a paixão ou o descontentamento dos indivíduos podem ser identificados através desse elemento e, dessa forma, possibilitam a correção de problemas num espaço curto de tempo, bem como o desfrute de novas oportunidades atreladas a esse tipo de vínculo emocional;

4. Influência: componente que inclui a possível recomendação de uma marca, produto ou serviço a familiares, amigos e conhecidos dos indivíduos, sobretudo através dos espaços de conversação presentes no ambiente virtual. Esse avançado estágio de engajamento abarca a consciência de marca, a lealdade e a possibilidade de recompra. E esse conjunto de informações, por sua vez, é essencial para a identificação do perfil da audiência e a posterior elaboração de novos planos estratégicos.

\section{PROCEDIMENTOS METODOLÓGICOS E RESULTADOS}

A coleta dos dados, no período indicado, gerou um corpus de 328 publicações relacionadas às IES analisadas, as quais a observação sistemática foi realizada. Nessa observação, foi possível identificar as ações de marketing relacionadas com as publicações, classificando-as por perfis e temas das postagens. O período selecionado, 
de $1^{\circ}$ de julho a 30 de setembro de 2018, para a captação de dados e análises deu-se pelo fato de o segundo semestre acadêmico ter alta concentração de eventos e processos internos nas universidades, que demandam, de certa forma, processos comunicacionais, que envolvem as publicações em redes sociais digitais.

Assim, em um primeiro momento, a análise de dados foi quantitativa, mostrando quantos comentários, curtidas e compartilhamentos as postagens receberam, e qualitativa de interação da conversa entre os usuários. O monitoramento das páginas oficiais do Facebook das duas IES foi fundamental para a coleta dos dados estatísticos e para posterior interpretação.

Para se calcular o índice de engajamento de uma página, a fórmula aplicada foi a já definida pelo próprio Facebook:

Engajamento $=$ Comentários + Curtidas + Compartilhamentos $\backslash$ total de fãs da página $X$ 100

A ferramenta utilizada para mensurar o engajamento das IES analisadas foi o Scup, em sua versão gratuita, que permitiu fornecer relatórios precisos sobre cada dia de pesquisa, em cada instituição.

Como resultados, as informações coletadas diretamente das duas páginas oficiais no Facebook da PUC Goiás e da UCDB, em 20 de outubro de 2018, mostraram que as primeiras têm 73.390 seguidores e 72.790 fãs; já a segunda possui 95.424 seguidores e 95.852 fãs.

$\mathrm{Na}$ análise da quantidade de publicação por dia, na Tabela 1, mostra os dados que configuram uma maior ação da UCDB sobre a PUC Goiás, com quase o dobro das postagens por dia.

Tabela 1 - Publicações / Média por dia

\begin{tabular}{lcc}
\hline Instituições & Publicações no período & Média de publicações por dia \\
\hline UCDB & 217 & 2,35 \\
PUC Goiás & 111 & 1,2 \\
\hline
\end{tabular}

Fonte: Pesquisa realizada pelos autores. 
Durante o período da análise, a IES de Goiás publicou 'praticamente' uma vez ao dia, com raras exceções. Já a Católica de Campo Grande fez duas ou mais postagens por dia, em média.

Outra relevante informação é o número de postagens por dia, durante o período avaliado. Ambas mantem suas páginas atualizadas e a UCDB tem mais de duas postagens todos os dias, conforme exposto na Tabela 2.

Tabela 2 - Curtidas, Comentários e Compartilhamentos

\begin{tabular}{lccc}
\hline Instituições & Curtidas (n) & Comentários (n) & Compartilhamentos (n) \\
\hline UCDB & 39831 & 727 & 2208 \\
PUC-Goiás & 5626 & 239 & 900 \\
\hline
\end{tabular}

Fonte: Pesquisa realizada pelos autores.

Por meio dos dados e da fórmula exposta, a Tabela 3 , indica o alto índice de engajamento da UCDB, 44, 62\%. A PUC Goiás não atingiu 10\% de engajamento.

Tabela 3 - Engajamento das páginas

\begin{tabular}{lc} 
Instituições & Taxa de engajamento (\%) \\
\hline UCDB & 44,62 \\
PUC-Goiás & 9,29 \\
\hline
\end{tabular}

Fonte: Pesquisa realizada pelos autores.

O engajamento da UCDB é reflexo do número de publicações que a Instituição faz em relação ao da PUC Goiás. Essa evidência demonstra que, além de estar mais ativa na mídia analisada, suas postagens estão atingindo de maneira mais assertivas seus públicos, e provocando neles o desejo da interação. É importante esclarecer que o engajamento é eficaz quando existe uma qualidade da interação e que a Universidade Católica Dom Bosco está com os processos de mídia digital na direção correta para atingir um público-alvo, pois detém um alto engajamento. 


\section{CONSIDERAÇÕES FINAIS}

Os resultados do estudo indicam que as mídias digitais permitem novas lógicas e possibilitam maior autonomia aos atores sociais na sua construção da visibilidade. Vivencia-se uma realidade que atores sociais individuais e coletivos agem por meio de discursos, relacionando-se de forma mediada e midiatizada. E as mídias sociais digitais se constituem como espaços de disputa de sentidos, em que as organizações atuam na busca de legitimação perante seus públicos e a sociedade.

Em função da questão apontada no início desse artigo, isto é, sobre o uso das redes sociais como ferramentas de marketing educacional pelas IES analisadas, foi possível compreender que as estratégias estão sendo adotadas adequadamente e com certa frequência. A resposta se deu a partir dos dados coletados na pesquisa, que apresentam forte engajamento das IES, gerando ações positivas de envolvimento, interação, intimidade e influência. Os quatro elementos citados são fatores fundamentais para o engajamento nas redes sociais, segundo Cerqueira e Silva (2011). Assim sendo, é possível considerar que a hipótese levantada teve êxito ao se evidenciarem os dados como número de seguidores e fãs, o engajamento e o perfil dos conteúdos apresentados durante o período.

O emprego da metodologia do monitoramento das páginas do Facebook aliada à leitura qualitativa permitiu reunir elementos que apontam para a produção de ações efetivas de marketing e o compartilhamento das informações pelos grupos e usuários das redes de movimentos sociais das universidades pesquisadas.

A partir dos dados coletados, reforça-se a ideia de uma maior autonomia das organizações em promover a sua visibilidade nas redes sociais digitais, que, para garantir bons resultados nesse âmbito, importa menos quem publica, e mais o potencial de conexão com o usuário.

A partir da reflexão e dos dados coletados, a perspectiva é de que a visibilidade midiática organizacional, no contexto de midiatização e mídias sociais digitais, constrói-se na articulação com o engajamento, gerado pela ativação de público-alvo e pela qualidade dos conteúdos escolhidos, disseminados via as redes sociais. Essa visão contempla a concepção de que a visibilidade de uma organização nas redes sociais digitais não diz respeito apenas à sua presença na rede, mas também a interaçãolrelação entre os atores envolvidos na construção dessa presença e a partir dela.

Tal constatação está embasada na observação de que a UCDB demonstra produzir conteúdo de qualidade e com assuntos que geram interesse pelos seus interlocutores, com isso explorando as redes sociais com uma excelente ferramenta de marketing educacional, em que os influenciadores, constatados pelos altos números de curtidas, 
pelo amplo aspecto de engajamento e pela solidez da positividade de suas postagens, chegam à métrica de alto impacto e visibilidade com suas ações.

Por fim, mas não mesmo importante, é imperativo citar que a UCDB está mais direcionada a alcançar melhores resultados pela característica de publicar e ter curtidas, assim como compartilhar assuntos que dão relevo aos atores na rede. $O$ fato de publicar temas de interesse do seu público gera maior interação e provoca um engajamento superior em relação à outra IES analisada. Nesse sentido, embora as duas tenham requisitos de marketing e engajamento digital, denota-se uma maior eficiência nas ações da Universidade Católica Dom Bosco.

\section{Notas}

${ }^{1}$ Informações colhidas no portal E-mec - fonte http://emec.mec.gov.br/emec/nova._Acesso em: 23 maio 2018.

${ }^{2}$ EduTrends 2016: benchmarks de Marketing Digital para instituições de ensino, no link https://inteligencia.rockcontent.com/relatorios/edu-trends-2016/._Acesso em: 10 set. 2018.

\section{Referências}

Barichello, E. M. M. R. (2014). Midiatização e cultura nas organizações da contemporaneidade: o processo de midiatização como matriz de práticas sociais.Em M. Marchiori (Org.), Contexto organizacional midiatizado (pp.37-45). Rio de Janeiro: Editora Senas.

Braga, J. L. (2012). Circuitos versus campos sociais. Em M. A. Mattos, J. Janotti Júnior e N. Jacks (Orgs.), Mediação e midiatização (pp.31-52). Salvador: EDUFBA.

Castro, V. J. (Org.) (2017). Comunicação e sociedade do espetáculo. São Paulo: Paulus.

Cerqueira, R. y Silva, T. (2011). Marcas e engajamento digital: algumas considerações. En W. Gomes e L. Reis (Orgs.), Publicidade digital: formatos e tendências da nova fronteira publicitária (pp.107-122). Salvador: P\&A Editora.

Di Felice, M. (2012). Redes sociais digitais, epistemologias reticulares e a crise do antropomorfismo social. Revista USP, (92), 6-19. https://doi.org/10.11606/issn.23169036.v0i92

Fausto Neto, A. (2008). Fragmentos de uma analítica da midiatização. Matrizes, 1(2), 89-105.

Ferreira, J. (2007). Midiatização: dispositivos, processos sociais e de comunicação. Revista ECompós, (10), 1-15.

Hjarvard, S. (2012). Midiatização: teorizando a mídia como agente de mudança social e cultural. Revista Matrizes, 5(2), 53-91. 
Hjarvard, S. (2015). A midiatização da cultura e da sociedade. São Leopodo: Editora Unisinos.

Kotler, P. (2017). Marketing 4.0: do tradicional ao digital. Rio de Janeiro: Sextante.

Martín-Barbero, J. (2009). Uma aventura epistemológica. Entrevistador: Maria Immacolata Vassallo de Lopes. Revista Matrizes, 2(2), 143-162.

Recuero, R. (2008). Redes sociais na internet (pp. 138-139). Porto Alegre: Sulina. (2012). A Conversação em rede (p. 12). Porto Alegre: Sulina. 


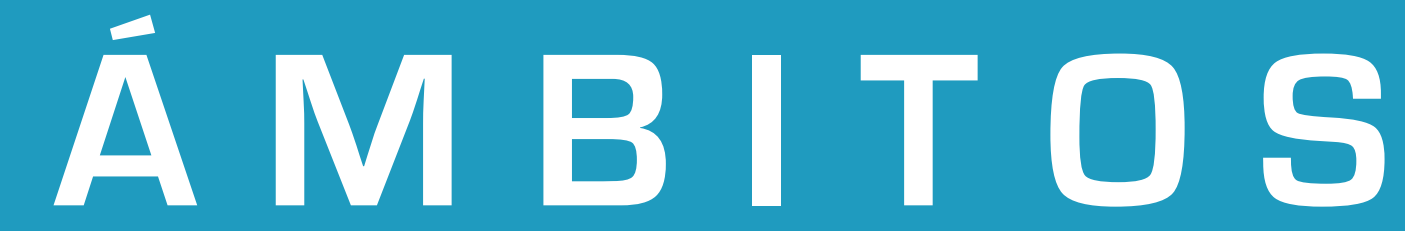

ISSN: 1139-1979 | ISSN digital: 1988-5733 | Depósito Legal: SE-1493-98

Revista Internacional de Comunicación editada por el Grupo de Investigación en Estructura, Historia y Contenidos de la Comunicación(GREHCCO) de la Universidad de Sevilla.

\section{ambitoscomunicacion@us.es}

http://institucional.us.es/ambitos

@RevistaAmbitos 